\title{
Characteristics of chest pain and its acute management in a low-middle income country: analysis of emergency department surveillance data from Pakistan
}

\author{
Nino Paichadze ${ }^{1 *}$, Badar Afzal ${ }^{2}$, Nukhba Zia ${ }^{1}$, Rakshinda Mujeeb², Muhammad Mujeeb Khan ${ }^{3}$, Junaid A Razzak ${ }^{4,5}$
}

\begin{abstract}
Background: Chest pain is one of the most frequent causes of emergency department (ED) visits in high-income countries. Little is known about chest pain patients presenting to EDs of low- and middle-income countries (LMICs). The objective of this study was to describe the characteristics of chest pain patients presenting to emergency departments (EDs) of Pakistan and to determine the utilization of ED resources in the management of chest pain patients and their outcomes.

Methods: This study used pilot active surveillance data from seven major EDs in Pakistan. Data were collected on all patients presenting to the EDs of the participating sites to seek emergency care for chest pain.

Results: A total of 20,435 patients were admitted to the EDs with chest pain. The majority were males (M 60\%, F $40 \%)$ and the mean age was 42 years (SD+/- 14). The great majority $(97 \%, n=19,164)$ of patients were admitted to the EDs of public hospitals compared to private hospitals and only $3 \%$ arrived by ambulance.

Electrocardiograms (ECGs) were used in more than half of all chest pain patients $(55 \%, n=10,890)$ while cardiac enzymes were performed in less than $5 \%$ of cases. Chest $X$-rays were the most frequently performed radiological procedure $(21 \%, n=4,135)$; more than half of the admitted chest pain patients were discharged from the EDs and less than $1 \%$ died in the ED.

Conclusion: Chest pain is a common presenting complaint in EDs in Pakistan. The majority received an ECG and the use of diagnostic testing, such as cardiac enzymes, is quite uncommon.
\end{abstract}

\section{Background}

Chest pain is a frequently occurring symptom affecting $20-40 \%$ of the general population worldwide [1-3]. It is responsible for more than 8 million visits to emergency departments (EDs) in the United States each year, making it the second most frequent cause of emergency visits [4] after stomach and abdominal pain [5]. Each year in England and Wales, approximately 15 million people visit EDs and $2.4 \%$ of attendances - representing 360,000 patient visits - are because of chest pain [6]. In the United States and Europe, up to $5 \%$ of visits to

\footnotetext{
* Correspondence: npaicha1@jhu.edu

'Johns Hopkins International Injury Research Unit, Department of International Health, Johns Hopkins Bloomberg School of Public Health, Baltimore, Maryland, USA

Full list of author information is available at the end of the article
}

emergency departments are due to chest pain $[7,8]$. The burden of cardiovascular disease in low-and middleincome countries (LMICs) has gained increased attention [9-11], though population-based data on the prevalence of chest pain in developing countries is lacking [12].

Chest pain can be cardiac (angina) as well as non-cardiac in origin [13-15]. Patients present with a wide spectrum of signs and symptoms reflecting several potential etiologies of chest pain including life-threatening, urgent conditions such as: myocardial infarction (MI), pulmonary embolism, or aortic dissection; and non-urgent conditions such as: musculoskeletal pain, gastro-esophageal reflux disease (GERD), pericarditis, or others [16]. Chest pain is the most common presenting complaint of an MI [17]. 
Studies identifying characteristics of chest pain are mostly from developed countries, hence the data on global prevalence of chest pain in developing countries is scant [12]. Examining the prevalence of chest pain - both angina (cardiac) and non-anginal (non-cardiac) - and its characteristics in LMICs is critical for developing targeted interventions for the management of chest pain patients in EDs and potentially stemming an epidemic of premature coronary deaths [9].

The objective of this paper is to look at characteristics of chest pain patients presenting to EDs of Pakistan and to determine the utilization of ED resources in the management of chest pain patients and their outcomes.

\section{Methods}

\section{Study setting and population}

The Pakistan National Emergency Departments surveillance (Pak-NEDS) was an active pilot surveillance conducted from November 2010 - March 2011 in seven major emergency departments in Pakistan: Aga Khan University (AKU) and Jinnah Post-graduate Medical Center in Karachi; Benazir Bhutto Hospital in Rawalpindi; Lady Reading Hospital in Peshawar; Mayo Hospital in Lahore; Sandeman Provincial Hospital in Quetta; and Shifa International Hospital in Islamabad. All the sites were tertiary care urban centers. The AKU and the Shifa International Hospital are private hospitals while the rest are public hospitals. AKU was the main coordinating center for the study. Ethical approval for the study was taken from all participating sites. Data was collected on males and females of all age groups presenting to the emergency departments of the participating sites to seek emergency care for various medical and surgical conditions including chest pain. The total number of patients enrolled during the study period was 274,436 . Chest pain as the major complaint and as the second and third presenting symptom was widely distributed among admitted patients. In this paper, we analysed only those who were admitted to the emergency departments with chest pain as a chief complaint.

\section{Data collection tool and team}

A one-page standardized tool was developed based on an ambulatory care survey tool from the Centers for Disease Control and Prevention, USA and previous surveillance work done in Pakistan [18]. The tool had questions related to patient demographics like age, gender, ethnicity; presenting complaints; treatment and management provided in the emergency department; provisional diagnosis; and disposition from the emergency department. Data collectors were specifically hired and trained for this study and they worked in three shifts giving twenty-four hour coverage. Data collection was done through patient/next of kin interviews and review of emergency department records.
Hard copies of the data collection tool were sent to the coordinating center at the AKU.

\section{Data analysis}

Data was entered at AKU using Epi Info ${ }^{\mathrm{TM}}$ version 3.3.2. All data were tabulated using Stata, version 12 (Stata Corp, College Park, TX) and SPSS version 20 (IBM Corp, Armonk, NY) and used simple descriptive analytic methods. Available data on admitted chest pain patients was classified using simple, one-way, two-way, and complex tabulation statistical methods; frequency distribution and percentage calculations were reported for categorical variables. During the Pak-NEDS study period, 20,435 patients were admitted to the EDs with chest pain as a major complaint. Only up to $1 \%(\mathrm{n}=2,907)$ of all patients were admitted to the ED with other major complaints where chest pain was noted as the second ( $\mathrm{n}=2,452,0.89 \%)$ or third ( $\mathrm{n}=455,0.17 \%)$ additional presenting complaint, respectively. This number was considered negligible and thus the analysis only focused on patients who were admitted to the ED with chest pain as the chief complaint.

Considering differences in the presentation and the clinical course of chest pain between the adult and pediatric populations, we focused only on adult patients, between the ages of 18 and 90 years old ( $n=19,752)$; correspondingly, patients younger than 18 years $(n=670,3 \%)$ and older than 90 years (90-98 age group, $n=13,0.06 \%$ ) were excluded from further analysis. This decreased the total sample size to 19,752 patients. Age distribution was studied in the following main groups (in years): 18-30, 31-45, 46-60, 61-75, 75-90, and 81-90. For the multiple-response variables such as physical examination, diagnostic and screening services, conducted procedures, and visit disposition, only single, all available response options were considered in the analysis. For the variables with missing data, the percentage of missing data is presented.

\section{Results}

Of the 19,752 patients, $58 \%(\mathrm{n}=11,419)$ were males and $39 \%(n=7,651)$ were females. Almost $35 \%(n=6,752)$ of all patients admitted with chest pain symptoms were in the $30-45$ age group and less than $2 \%(n=360)$ were in the 75-90 age group. The mean age of all admitted patients was 42 years $(S D \pm 14)$. Age distribution as well as the mean age was similar among men and female (male: 42.14 \pm 13.67 years, female: $41.53 \pm 16.58$ years) (Figure 1 and Table 1).

Nearly $97 \%$ ( $n=19,164)$ of all chest pain patients were admitted to the ED of public hospitals and since the number of patients admitted to private hospitals was low $(3 \%, \mathrm{n}=588)$, the analysis did not stratify results by hospital type. Less than $3 \%(n=585)$ were delivered to the hospital by ambulance and $92 \%$ used other modes of 


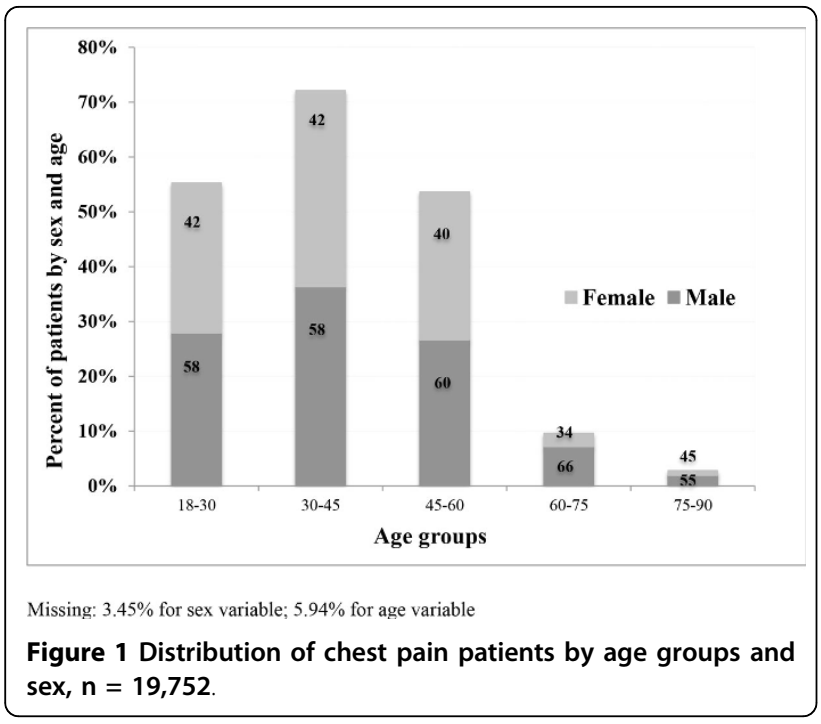

transportation. Almost 18\% $(\mathrm{n}=3,471)$ of all admitted chest pain patients had been treated for chest pain in the last 72 hours before their current visit to the emergency department. For the majority of patients $(84 \%, \mathrm{n}=$ $16,532)$, this was the first episode of care for chest pain, and for $31 \%(n=6,072)$, this was the first visit to the ED within the last 12 months (Table 1).

Review of the performed diagnostic and screening services showed that electrocardiograms (ECGs) were performed for more than half $(55 \%, \mathrm{n}=10,890)$ of patients. Chest X-rays were the most frequently performed diagnostic test and were used in up to $21 \%(\mathrm{n}=4,135)$ of patients; cardiac enzymes were measured in only $5 \%(n=1,010)$, with as low as $1 \%(\mathrm{n}=224)$ measured among females (Table 2).

Overall, $16 \%(n=3,158)$ of patients with chest pain were admitted to the hospitals, slightly higher for males compared to females (17\% vs. $15 \%)$. A total of $157(0.8 \%)$ of patients with chest pain died in the emergency department. The mortality rate was $25 \%$ higher for males compared to females $(0.9 \%$ vs. $0.7 \%$, p-value $=0.00)$.

\section{Discussion}

This study looked at the characteristics of chest pain patients presenting at selected EDs in Pakistan. The analysis showed that more than $7 \%$ of all admitted patients had a complaint of chest pain. This finding is consistent with the numbers cited in published sources, which show that the prevalence of chest pain patients in EDs ranges between $2.4 \%$ and $20 \%$ in the United States, UK, and Europe $[1,4,7,19]$. Unfortunately, available literature on the burden of chest pain is limited to developed country settings only. Most literature from LMICs describes the prevalence, patterns, and risk factors of coronary heart
Table 1 Main characteristics of chest pain patients (n = 19,752)

\begin{tabular}{|c|c|c|}
\hline \multicolumn{3}{|c|}{ History of visit $n(\%)$} \\
\hline \multirow[t]{2}{*}{ Sex } & Male & $11,028(60)$ \\
\hline & Female & $7,515(40)$ \\
\hline \multirow[t]{5}{*}{ Age } & $18-30$ & $5,181(27.9)$ \\
\hline & $31-45$ & $6,752(36.3)$ \\
\hline & $46-60$ & $4,949(26.6)$ \\
\hline & $61-75$ & $1,336(7.2)$ \\
\hline & $75-90$ & $360(1.9)$ \\
\hline \multirow[t]{2}{*}{ Mode of arrival at EDs } & Ambulance & $585(2.9)$ \\
\hline & $\begin{array}{l}\text { Non- } \\
\text { ambulance }\end{array}$ & $\begin{array}{l}18,150 \\
(91.9)\end{array}$ \\
\hline \multirow[t]{2}{*}{ Hospital } & Public & $\begin{array}{c}19,164 \\
(97.0)\end{array}$ \\
\hline & Private & $588(3.0)$ \\
\hline \multirow[t]{2}{*}{ Treated for chest pain in last $\mathbf{7 2}$ hours } & Male & $1,888(54.4)$ \\
\hline & Female & $1,546(44.5)$ \\
\hline \multirow[t]{3}{*}{ Episode of care } & First visit & $\begin{array}{l}16,532 \\
(83.7)\end{array}$ \\
\hline & Follow-up visit & $643(3.2)$ \\
\hline & Don't know & $85(0.4)$ \\
\hline \multirow{6}{*}{$\begin{array}{l}\text { Number of ED visits within last } 12 \\
\text { months }\end{array}$} & 0 & $6,072(30.7)$ \\
\hline & 1 & $3,750(18.9)$ \\
\hline & 2 & $1,198(6)$ \\
\hline & 3 & $540(2.7)$ \\
\hline & $4-10$ & $518(2.6)$ \\
\hline & Don't know & $173(0.9)$ \\
\hline
\end{tabular}

Missing: $5.13 \%$ for the mode of arrival variable; $3.55 \%$ for treatment in last 72 hours variable; $18.04 \%$ for discharged in last 7 days variable; $12.62 \%$ for episode of care variable; $37.89 \%$ for number of ED visits last year variable; $26.96 \%$ for triage variable

disease (CHD) and MI [20-22], but information on chest pain as a symptom is scarce.

Patients presenting with chest pain were found to be young, with a mean age of 42 years and more likely to be males. This trend is comparable with other reports showing that patients with an MI from LMICs were younger than patients from high-income countries (HICs) [23-26][27]. An overall younger population, differences in risk factors, and socioeconomic disparities between populations in HICs and LMICs [24] could explain the higher prevalence of CHD in relatively young patients in Pakistan [28].

Pakistan has variable ambulance service quality with uneven coverage [29]. The findings of this study are in line with the already available evidence: most of the patients presented to the EDs used other means of transportation than ambulance service, which highlights the lack of pre-hospital care in Pakistan and thus may be a contributing factor to delayed presentation to the 
Table 2 Imaging and disposition distribution based on gender and age groups $(\mathbf{n}=19,752)$

\begin{tabular}{|c|c|c|c|c|c|c|c|}
\hline \multirow[t]{2}{*}{ Sex } & \multirow[t]{2}{*}{ Imaging and Tests } & \multicolumn{5}{|c|}{ Age groups } & \multirow[t]{2}{*}{ Total } \\
\hline & & $18-30$ & $31-45$ & $46-60$ & $61-75$ & $76-90$ & \\
\hline \multirow[t]{4}{*}{ Males } & Cardiac enzymes & $28(0.9)$ & $296(7.5)$ & $380(12.5)$ & $76(8.7)$ & $6(3.0)$ & $786(7.1)$ \\
\hline & ECG & $1,357(44.9)$ & $2,488(63.0)$ & $2,052(68.8)$ & $618(70.3)$ & 134(67.3) & $6,649(60.3)$ \\
\hline & X-Ray & $795(26.3)$ & $849(21.5)$ & $599(20.1)$ & 188(21.4) & 49(24.6) & $2,480(22.5)$ \\
\hline & Total males in each age group & 3,021 & 3,948 & 2,981 & 879 & 199 & 11,028 \\
\hline \multirow[t]{4}{*}{ Females } & Cardiac enzymes & $13(0.6)$ & $69(2.5)$ & 103(5.4) & $27(6.0)$ & $12(7.5)$ & $224(3.0)$ \\
\hline & ECG & $943(44.5)$ & $1,538(55.7)$ & $1,312(68.2)$ & $325(72.3)$ & $122(76.3)$ & $4,240(57.2)$ \\
\hline & X-Ray & $536(25.3)$ & $618(22.4)$ & 382(19.9) & $82(18.3)$ & $37(23.1)$ & $1,655(22.3)$ \\
\hline & Total females in each age group & 2,119 & 2,763 & 1,924 & 449 & 160 & 7,415 \\
\hline \multirow[t]{2}{*}{ Sex } & Disposition & & & ge groups & & & Total \\
\hline & & $18-30$ & $31-45$ & $46-60$ & $61-75$ & $76-90$ & \\
\hline \multirow[t]{4}{*}{ Males } & Discharged & $1,674(55.1)$ & $2,275(57.6)$ & $1,503(50.4)$ & $362(41.2)$ & $83(41.7)$ & $5,897(53.5)$ \\
\hline & Admitted & $327(10.8)$ & $580(14.7)$ & $736(24.7)$ & 273(31.1) & $64(31.2)$ & $1,980(18.0)$ \\
\hline & Died & $11(0.4)$ & $21(0.5)$ & $44(1.5)$ & 26(3.0) & $2(1.0)$ & 104(0.9) \\
\hline & Total males in each age group & 3,021 & 3,948 & 2,981 & 879 & 199 & 11,028 \\
\hline \multirow[t]{4}{*}{ Females } & Discharged & $1,084(51.2)$ & $1,520(55.0)$ & $941(48.9)$ & 196(43.6) & $69(43.1)$ & $3,810(51.4)$ \\
\hline & Admitted & 231(10.9) & $331(12.0)$ & $449(23.2)$ & 119(26.5) & $48(30.0)$ & $1,178(15.9)$ \\
\hline & Died & $9(0.4)$ & $7(0.3)$ & $22(1.1)$ & $9(2.0)$ & $6(3.8)$ & $53(0.7)$ \\
\hline & Total females in each age group & 2,119 & 2,763 & 1,924 & 449 & 160 & 7,415 \\
\hline
\end{tabular}

ED. Distance to facility was also found to be an important factor leading to delay in presentation, prolonging total time until treatment and resulting in worse outcomes in patients [30]. However, these variables were not recorded in this study.

Type and duration of chest pain, findings on the ECG and chest $\mathrm{x}$-ray, and in some cases biomarkers are primary modalities used for triaging patients with chest pain in the emergency department. ECG is considered critical for decision-making; in many high-income settings, ECG done within 10-15 minutes of presentation to emergency department is considered one of the indicators for quality of care in chest pain management in the emergency department. In this study, only $55 \%$ of patients with chest pain had an ECG in the emergency department, with a higher rate shown in older patients. Additionally, biomarkers were rarely used in the emergency department, perhaps due to non-availability of the tests in the emergency department.

Less than $20 \%$ of all patients with chest pain were admitted to the hospital. This is a relatively low number of admission compared to findings in the US (35\%) [31], but comparable to findings in the UK (25\%) [6]. As previous research shows, only $10-15 \%$ of patients with chest discomfort have an acute MI, and most chest pain patients do not have significant disease [32-34]. Nevertheless, evidence from developed countries illustrates that physicians often fail to correctly diagnose an MI in patients with atypical signs and symptoms with as many as $4-13 \%$ of patients with an MI being discharged erroneously from the ED [32-34]. Because of this failure in the traditional approach to patients with chest pain, EDs in most developed countries started implementing chest pain units (CPUs) with designated resources of personnel, protocols, space, and equipment for patients presenting with chest pain [32]. Admission rates in Pakistan represent multiple factors working together, such as the prevalence of disease in the population, training and clinical practice of the providers, availability of resources such as hospital beds, and the preference of patients. Most of the care in our study was provided through government-run public hospitals. These hospital emergency departments are extremely busy with an average daily ED census between 400-1000. With such a high volume of patients, practitioners are likely to focus on patients with obvious findings on a clinical exam or ECGs. It is also not clear how many of these patients had a follow-up arranged during their visit to the emergency department and how many actually had an appropriate follow-up.

\section{Limitations}

The Pak-NEDS study has several limitations, some of which were mentioned above. Due to a lack of a large amount of clinical information, analyses did not explore in detail: the characteristics of chest pain (duration of the symptom before visiting ED, character and site of pain, precipitating factors, etc.); risk factors and patient history (smoking status, diabetes, systolic blood pressure, etc.); the results of conducted screening and diagnostic tests; provisional diagnoses; or conducted treatment. Furthermore, 
we could not determine whether any chest pain management algorithms, diagnostic protocols, and guidelines were used and followed for the management of chest pain patients in the EDs.

The issue of missing information could partially be explained by poor documentation of symptoms, conducted diagnostic tests, provided treatment, and discharge diagnosis by medical staff. Thus, it is difficult to pass judgment on the use of ED resources in the management of chest pain patients. Clinical documentation should be inherent to every patient encounter [35]. Complete and accurate patient record documentation is vital for improving quality and continuity of care [36], and is critical for accumulating evidence about the burden, epidemiology, and management of a disease. Establishing an organized system for the documentation of medical information should become a target for interventions implemented both at hospital and health systems levels in LMICs.

The participating sites were general EDs, but there are some centers in Pakistan specialized to handle chest pain patients; therefore, the results may underestimate the true picture of chest pain burden in Pakistan. Finally, the pilot surveillance study does not include information on the follow-up of chest pain patients, which makes it difficult to learn about the long-term effects of chest pain management in the EDs in Pakistan.

\section{Conclusion}

In conclusion, the findings of this study showed a high burden of chest pain in Pakistan, with higher numbers in younger adults. There is a gap between international evidence on the management of chest pain patients and practice in Pakistan. Globally, closing the gap between evidence and practice has focused on individual clinician and institutional approaches, including the use of clinical practice guidelines and protocols [37-39]. This study attempted to close this gap by showing a relatively high prevalence of ED adult chest pain presentations. It highlights the importance of having surveillance registry in Pakistan and other LMICs to help determine the prevalence of common disease presentations and dispositions, and demonstrates key limitations in data acquisition related in part to poor documentation of clinical information. Further research and development strategies should focus on improving medical documentation and data collection to improve surveillance as a basis for ultimately establishing evidence on quality of care delivery for key clinical presentations to EDs in LMICs.

\section{Competing interests}

The authors declare that they have no competing interests.

\section{Authors' contributions}

NP led the development of initial and revised manuscript; BA and RM reviewed and provided extensive feedback on various versions of the manuscript. NP performed data management and analysis and NZ helped with the process of analysis. NZ, MMK and JR critically reviewed the draft and all authors approved the final version of the manuscript.

\section{Acknowledgements}

The authors would like to acknowledge the data collectors at all the sites. We are grateful to Ms. Leann Rosenberg who proof-read the manuscript for language edits. The Pak-NEDS study was supported through the "Johns Hopkins International Collaborative Trauma and Injury Research Training Program" [Grant No. D43TW007292] by Fogarty International Center of the United States National Institutes of Health. The content is solely the responsibility of the authors and does not represent the views of Fogarty or $\mathrm{NIH}$.

This article has been published as part of BMC Emergency Medicine Volume 15 Supplement 2, 2015: Articles from the Pakistan National Emergency Departments Surveillance Study (Pak-NEDS). The full contents of the supplement are available online at http://www.biomedcentral.com/ bmcemergmed/supplements/15/S2. Publication of this supplement was funded by the Johns Hopkins School of Public Health.

\section{Authors' details}

${ }^{1}$ Johns Hopkins International Injury Research Unit, Department of International Health, Johns Hopkins Bloomberg School of Public Health, Baltimore, Maryland, USA. ${ }^{2}$ Department of Emergency Medicine, Aga Khan University, Karachi, Pakistan. ${ }^{3}$ Benazir Bhutto Hospital, Rawalpindi, Pakistan. ${ }^{4}$ Department of Emergency Medicine, John Hopkins School of Medicine, Baltimore, Maryland, USA. ${ }^{5}$ The author was affiliated with the Department of Emergency Medicine, Aga Khan University, Karachi, Pakistan at the time when study was conducted.

Published: 11 December 2015

\section{References}

1. Ruigomez A, Rodriguez LAG, Wallander M-A, Johansson S, Jones R: Chest pain in general practice: incidence, comorbidity and mortality. Family Practice 2006, 23(2):164-174.

2. Wong WM, Lam KF, Cheng C, Hui WM, Xia HH-X, Lai KC, Hu WHC, Huang JQ, Lam CLK, Chan CK, et al: Population based study of noncardiac chect pain in southern Chinese: prevalence, phychocosocial factors and health care utilization. World J gastroenterol 2004, 10(5):707-712.

3. Eslick GD, Jones MP, Talley NJ: Non-cardiac chest pain: prevalence, risk factors, impact and consulting - a population-based study. Aliment Pharmacol Ther 2003, 17:1115-1124.

4. Amsterdam EA, Kirk D, Bluemke DA, Diercks D, Farkouh ME, Garvey JL, Kontos MC, McCord J, Miller TD, Morise A, et al: Testing of low-risk patients presenting to the emergency departmet with chest pain: A scientific statement from the American Heart Association. Circulation American Heart Association 2010, 122:1756-1776.

5. Centers for Disease Control and Prevention: National Hospital Ambulatory Medical Care Survey: 2010 Emergency Department Summary Tables. 2010.

6. Goodacre S, Cross E, Arnold J, Angelini K, Capewell S, Nicholl J: The health care burden of acute chest pain. Heart 2005, 91:229-230.

7. Groarke J, O'Brien J, Go G, Susanto M, Owens P, Maree AO: Cost burden of non-specific chest pain admissions. Ir J Med Sci 2013, 182:57-61.

8. Graff LG, Dallara J, Ross MA, Joseph AJ, Itzcovitz J, Andelman RP, Emerman C, Turbiner S, Espinosa JA, Severance H: Impact on the care of the emergence department chest pain patient from the Chest Pain Evaluation Registry (CHEPER) Study. American Journal of Cardiology 1997, 80:563-568.

9. Zaman MJS, Mola CLd, Gilman RH, Smeeth L, Miranda JJ: The prevalence of angina symtpms and association with cardiovascular risk factors, among rural, urban and rural to urban migrant populations in Peru. BMC Cardiovascular Disorders 2010, 10(50).

10. Miranda JJ, Kinra S, Casas JP, Smith GD, Ebrahim S: Non-communicable diseases in low- and middle-income countries: cotext, determinants and health policy. Trop Med Int Health 2008, 13(10):1225-1234.

11. Strong K, Mathers C, Leeder S, Beaglehole R: Preventing chronic diseases: how many lives can we save? lancet 2005, 366:1578-1582. 
12. Hemingway $H$, Langenberg $C$, Damant J, Frost $C$, Pyorala $K$, barrett-Connor $E$ : Prevalence of angina in women versus men: a systematic review and meta-analysis of international variations across 31 countries. Circulation 2008, 117:1526-1536.

13. Karlson BW, Herlitz J, Pettersson P, Ekval HE, Hjalmarson A: Patients admitted to the emergency room with symptoms indicative of acute myocardial infarction. Journal of Internal Medicine 1991, 230:251-258.

14. Lee TH, Cook EF, Weisberg M, Sargent K, Wilson C, Goldman L: Acute chest pain in the emergency room: identification and examination of low-risk patients. Arch Intern Med 1985, 145:65-69.

15. Parsonage WA, Cullen L, Younger JF: The approach to patients with possible cardiac chest pain. MJA, Cardiology Series - 2 2013, 199(1):1-5.

16. Backus BE, Six AJ, Kelder JH, Gibler WB, Moll FL, Doevendans PA: Risk scores for patients with chest pain: evaluation in the mergency department. Current Cardiology Reviews 2011, 7:2-8.

17. Malik MA, Khan SA, Safdar S, Taseer I-U-H: Chest pain as a presenting compaint in patients with acute myocardial infarction (AMI). J Med Sci 2013, 29(2):565-568.

18. Razzak JA, Shahim MS, Mehmood A, Hussaid SA, Ali MS, Jooma R: A successful model of road traffic injury surveillance in a developing country: process and lessons learnt. BMC Public Health 2012, 12(357)

19. Martinez-Selles M, Bueno H, Sacristan A, Estevez A, Ortiz J, gallego I, Fernandez-Aviles F: Chest pain in the emergency department: incidence, clinical characteristics, and risk stratification. Rev Esp Cardiol 2008, 61(9):953-959.

20. Celermajer DS, Chow CK, Marijon E, Antsey NM, Woo KS: Cardiovascular disease in developing world: prevalence, patterns, and the potential of early disease detection. Journal of American College of Cardiology 2012, 60(14):1207-1216.

21. The Earth Institute at Columbia University, Columbia University Mailman School of Public Health, University of Sydney Australian Health Policy Institute: A race against time: the challenge of cardiovascular disease in developing countries. New York: Columbia University 2004.

22. World Health Organization: Priority noncommunicable diseases and conditions. Health in Asia and the Pacific. Geneva, Switzerland: World Health Organization 2008

23. Gersh BJ, Sliwa k, Mayosi BM, Yusuf S: The epidemic of cardiovascular disease in the developing world: global implications. European Heart Journal 2010, 31:642-648.

24. Shimony A, Grandi SM, Pilote L, Joseph L, O'Loughlin J, Paradis G, Rinfret S, Sarrafzadegan N, Adamjee n, Yadav r, et al: Utilization of evidence-based therapy for acute coronary syndrome in high-income and low/middleincome countries. The American Journal of Cardiology 2014, 113(5):793-797.

25. Yusuf S, Hawken S, Ounpuu S, Dans T, Avezum A, Lanas F, McQueen M, Budaj A, Pais P, Varigos J, et al: Effect of potentially modifiable risk factors associated with myocardial infarction in 52 countries (the INTERHEART study): case-control study. lancet 2004, 364:937-952.

26. Gao R, patel A, gao W, Hu D, Huang D, Kong L, Qi W, Wu Y, Yang Y, Harris P, et al: Prospective observational study of acute coronary syndromes in China: practice patterns and outcomes. Heart 2007, 94:554-560.

27. Arshad S, Dhakam S, Awan S: Outcomes in ST elevation myocardial infarction; a comparison of a tertuary care center in Pakistan with European centers. J Pak Med Assoc 2011, 61(1215-1219).

28. Gill BUA, Ramzan M, Ahmed N, Abbas T, Qureshi BA, Saleemi MS, Zafar MZ, Sherwani M, Zaib J: Efficacy of streptokinase in diabetic and non-diabetic patients presenting with acute elevation myocardial infarction. Pak Heart J 2014, 47(2):96-99.

29. Karani R, Chandran A, Ejaz K: Insights on the effects of patient perceptions and awareness on ambulance usage in Karachi, Pakistan. Johns Jopkins Bloomberg School of Public Health, International Injury Research Unit and The Aga Khan University, Department of Emergency medicine 2013.

30. Rivzi S-F-u-H, Bajwa S-u-R, Mustafa G, Khurram D, Niaz A, Akhtar S, Javaid A, Mahmood S, Masood J, Asghar K: Prompt delivery of thrombolytic therapy: experience with chest pain units and emergency medical services. JPMA 2013, 163:194-199.

31. Bhuiya FA, Pitts SR, McCaig LF: Emergency department visits for chest pain and abdominal pain: United States, 1999-2008. NCHS Data Brief. Centers for Disease Control and Prevention 2010, 43.

32. American College of Emergency Physicians: Chest pain units in emergency department. A Report from the Short Term Observation Services Section Revised August 8, 1994. American College of Emergency Physicians 1994.
33. Rouan GW, Hedges JR, Toltzis R, Goldstein-Wayne B, Brand D, Goldman L: A chest pain clinic to improve the follow-up of patients released from urban university teaching hospital emergency department. Annals of Emergency Medicine 1987, 16(10):1145-1150.

34. Goldman L, Cook F, Brand DA, Lee TH, Rouan GW, Weisberg MC, Acampora D, Stasiulewicz C, Walshon J, Terranova G, et al: A computer protocol to predict myocardial infarction in emergency department patients with chest pain. The New England Journal of Medicine 1988, 318(13):797-803.

35. American Health Information Management Association: Poor documentation hazardous to patient health. 2014

36. Group Health: Medical records and documentation standards. 2013.

37. Mehta RH, Montoye CK, Gallogly M, Baker P, Blount A, Faul J, Roychoudhury C, Borzak S, Fox S, Franklin M, et al: Improving quality of care for acute miocardial infarction. JAMA 2002, 287(10):1269-1276.

38. Skolnick AH, Alexander KP, Chen AY, Roe MT, Pollack CV, Ohman M, Rumsfeld JS, Gibler WB, Peterson ED, Cohen DJ: Characteristics, management, and outcomes of 5,557 patients age $\geq 90$ years with acute coronary syndromes. Journal of the American College of cardiology 2007 49(17):1790-1797.

39. Rogers WJ, Canto JG, Lambrew CT, Tiefenbrunn AJ, Kinkaid B, Shoultz DA, Frederick PD, Every N: Temporal trends in the treatment of over 1.5 million patients with myocardial infarction in the US from 1990 through 1999. Journal of American College of Cardiology 2000, 36(7):2056-2063.

\section{doi:10.1186/1471-227X-15-S2-S13}

Cite this article as: Paichadze et al.: Characteristics of chest pain and its acute management in a low-middle income country: analysis of emergency department surveillance data from Pakistan. BMC Emergency Medicine 2015 15(Suppl 2):S13.

\section{Submit your next manuscript to BioMed Central and take full advantage of:}

- Convenient online submission

- Thorough peer review

- No space constraints or color figure charges

- Immediate publication on acceptance

- Inclusion in PubMed, CAS, Scopus and Google Scholar

- Research which is freely available for redistribution 